\title{
Discussion on education strategies of personality integrity for young athletes in China
}

\author{
Zhang Fan ${ }^{1,2, ~ a, ~}{ }^{*}$ Zhou Bo ${ }^{1, b}$ and Jia Changzhi ${ }^{1, c}$ \\ ${ }^{1}$ Department of Police Skills and Tactics, Nanjing Forest Police College, Nanjing 210023, China \\ ${ }^{2}$ Sports Science postdoctoral programme, Nanjing Normal University, Nanjing 210023, China \\ a zhangfan@nfpc.edu.cn, ${ }^{\mathrm{b}}$ zhoubo@nfpc.edu.cn, ${ }^{\mathrm{c}}$ jiachangzhi@nfpc.edu.cn \\ *corresponding author
}

Keywords: personality integrity, young athletes, culture education, sports training social practice.

\begin{abstract}
At present, China is in the key node of social transformation, and the market economy already has a series of problems, which need to be reformed. In this process, the wrong thoughts, such as money worship and individualism, have a greater influence on young athletes, and many of them turn to have different levels of personality defects, such as decline of ideology, decline of moral standards and the increase of violence behavior. Therefore, there is an urgent need to strengthen personality education, eliminate psychological barriers, and make up some of the personality defects of young athletes. This paper intends to explore the basic principles of personality integrity education, and put forward the corresponding implementation strategies, in order to promote individual physical and mental development of young athletes and provide reference for the sustainable development of sports undertakings.
\end{abstract}

\section{Introduction}

The essence of education is to educate people and the core of educating people is to shape their personality. It is the same for young athletes with the sports as the supporter and the championship as the purpose. Personality is the foundation of one's life. If athletes do not have a sound personality and noble character, even if he has the highest level of competition and good athletic performance, it is difficult to for them to obtain success and to be recognized by the society. With the rapid development of economy and society, due to influencing by the wrong thoughts, such as money worship and individualism, young athletes have different levels of personality defects, such as decline of ideology, decline of moral standards and the increase of violence behavior. There is an urgent need to strengthen personality education, eliminate psychological barriers, and make up some of the personality defects of young athletes. It not only focuses on reality and solves lots of problems in the process of training young athletes, but also focuses on the future and solves the urgent need for young athletes to develop in an all-round way, as well as the sustainable development of sports undertakings.

In order to shape young athletes to become people with personality integrity, we should help them gradually make the scientific value idea and the striving life attitude and sound self- consciousness. Young athletes should have the well emotion quality, volition quality, noble morality quality, effective cognitive way, deep competitive level, and so on, so that their personality has been fully developed. We can know the personality characteristics of young athletes by observing and evaluating methods, and fully understand their strengths and weaknesses. According to the laws of education and psychology, we put forward the measures for improving the young athletes, or make up the flaws of their personalities, in order to train the personality characteristic which conforms to the modern social development for outstanding sports talented person and form the perfect personality. 


\section{The Basic Principles of Personality Integrity Education}

\subsection{Pay attention to all-rounded principle in concept}

Personality education emphasizes the respect for human beings, regards the accomplishment and perfection of the educated themselves as the object, and pays attention to the guidance and inspiration of the way of being a person [1]. At present, the training mode for young athletes, emphasizes the champion and ignore the education, and emphasizes being the talent and ignores being a person. This kind of training activities starts from instrumentalism and pragmatism and understands the talent training as the training activities for a certain purpose. And the young athletes who are involved in the training activities are kind of tool for achieving a certain purpose (the Olympic strategy) and accomplish a certain task (striving for winning medals). From the point of view of the cultivation of athletic talents, this training mode trains a group of athletes who are simple minded person and well-developed limbs and cultivates quite a lot of competition machines.

\subsection{Pay attention to harmonization principle in value orientation and purpose}

The traditional training mode for competitive sports talents pays more attention to the physical structure of personality structure, and focuses on the acquisition of competitive ability and the development of skills and tactics, while the lack of sufficient attention to various factors related to social behavior, such as emotion, volition, interpersonal relationship, value concept and so on, leads to the formation of the abnormal personality. The personality education believes that no matter what kind of education, its true value should lie in the cultivation of sound personality. Even the concept aiming at training young athletes to win the Olympic champion, should also add the coordination of intelligence, affection, volition and behavior and mutual promotion into the training objectives and processes.

\subsection{Pay attention to adaptability principle in function}

The essential requirement of personality education is to regard young athletes as a whole body of life, rather than the passive cognitive body or a tool for winning medals. The personality education should not only respect their rights, but also respect their needs for self-development and self-improvement in their study, life and training.

\subsection{Pay attention to integrity principle in object}

There is no doubt that the cultivation of young athletes has its instrumental value and the utilitarian pursuit and serves for the national strategy, the sports undertaking and the society [2]. Accordingly, the cultivation of competitive sports talents should also have the social functions, such as economic, political, cultural and sport function, striving for medals, individually applying for job and making a living, etc. However, the essential function and intention of young athletes training is to educate people. The smooth implementation of the educational function is the most critical, as well as the basic channel for social function to be fully displayed.

\subsection{Pay attention to internality principle in mean}

Personality education emphasizes the internalization of education. It means that personality factors can only be internalized into their psychological information in the process of training young athletes and young athletes fully display certain moderating effects at the psychological level at the same time. Such an education can show the real results. Therefore, the key to personality education is to cultivate young athletes' ability of self-awareness, self-awareness, self-awareness and self adjustment and we should avoid regarding the training process of young athletes as an external control process. 


\section{Implementation Strategy of Personality Integrity Education}

\subsection{Implement personality education in culture education and sports training}

The two positions of culture education and sports training are the key ways to train young athletes' sound personality and implement personality education. Therefore, in the process of culture teaching or sports training, teachers and coaches should consciously and systematically combine the training of cultural knowledge and the cultivation of competitive ability, and carry out personality education for young athletes [3,4]. As educators, teachers and coaches must excavate and reorganize information conveying personality education in the process of cultivation process, and combine the information with psychological education. At the same time, teachers and coaches integrate the subject knowledge and skills, carry out scientific thinking methods, and achieve the construction and cultivation of young athletes' personality integrity from various angles. In the specific culture teaching and sports training, we should pay attention to the creation of a harmonious, equal and democratic educational environment, stimulate interest and maintain active thinking. Encourage the communication between teachers and students, so that young athletes with different cultural achievements and different levels of competition can achieve different levels of success with their own characteristics [5]. And young athletes can independently form sufficient confidence, and dare to express their own special views, not blindly follow the crowd. We promote them to excavate the nutrition from what they learn, and then further produce correct outlook of life, values and the world. We support them to interpret their personal true value tendencies and feelings, and then create a perfect personality trait. It must be emphasized that young athletes have the strong ability to imitate and have the excellent plasticity. They often regard coaches as the growth models, so the coaches' behaviors will undoubtedly have the significant positive or negative effect on the mental level for young athletes, and even the lifelong effect. This effect cannot be substituted by all the words and deeds of discipline and disciplinary measures.

\subsection{Implement personality education in social practice}

The same as the two positions of culture education and sports training, it is undoubtedly another main measure to promote the personality education of young athletes, which is also the lack of education part in the competitive sports institutions. Moreover, compared with the class teaching and sports training, social practice is more conducive to young athletes to exert their subjective initiative. Because in most social practices, teachers and coaches are mentors, and young athletes become masters of their activities. In the activities, they can do anything based on their own interests, desires and intentions, break man-made limitation by the classroom education and sports training, and change the leading status of teachers and coaches, so that they can show their ability and cleverness more freely and effectively and fully exert their autonomy, independence and creativity. Moreover, most of the social practices are collective activities, requiring much more solidarity and cooperation, which is conducive to the cultivation of cooperative spirit, cooperation consciousness, helping to improve the ability of young athletes' evaluation and self-evaluation. Therefore, social practice is a free world for young athletes to get all-round and full development. Therefore, it is necessary to optimize the social practice system, to set up sports idols and advocate noble personality as the content, through a variety of practical activities to cultivate excellent personality.

\subsection{Implement personality education in group living}

The particularity of the training process of young athletes leads to the fact that they are not isolated individuals. There is no doubt that most of their time is spent in the group. Those group living, learning and training and style of class, style of team, school spirit and style of study will make a deep brand for young athletes' personality formation [6]. The unified standards and common requirements of group living in competitive sports institutions are of great importance to the quality of commonality in shaping personality. The well school spirit, the unity of the class, a good teacher-student relationship, the relation between sports team mate, the organization activities of 
young pioneers, social service activities and arrangement visits play a profound role and effect in cultivating the discipline of young athletes, building a good team spirit, and setting up collective consciousness and perfect personality traits.

\subsection{Implement personality education in psychological counselling and guidance}

For competitive sports schools, teachers with expertise and skills or coaches can perform this work. Specific details of implementation can be added to the training program. This kind of coaching should aim at training young athletes' good personality quality or adjusting their bad personality psychology. On the one hand, the form of sports teams with young athletes as the core and teachers as the auxiliary, in the content level, fully refers to their realistic need in the personality development, and take positive effects, adjust individual mentality, and shape excellent personality. On the other hand, through the one-to-one communication with young athletes, or the coaches participating in their activities, we can help them to get rid of psychological state or adverse problems, deal with psychological problems what they face, and find a way to solve the psychological problems to improve their mental health.

\subsection{Permeate personality education in campus culture construction}

Campus culture is undoubtedly the most distinctive characteristic of social culture, which is closely related to society by young athletes and teachers in a special atmosphere, meanwhile has the humanistic characteristics, campus spirit and living environment of competitive sports institutions. In the free time after the learning and training, young athletes can take opportunities to participate in the colorful campus culture and entertainment, in order to achieve physical and mental pleasure, regulate individual mentality and maintain good mood. In addition, campus culture also helps young athletes develop a positive attitude towards life and build a harmonious interpersonal relationship.

\subsection{Combining three aspects of the school, family and society education, to make efforts to enhance the personality of young athletes' education}

As mentioned above, for competitive sports institutions, we should carry out personality education through class teaching, sports training, social practice activities, group living, campus cultural construction and psychological guidance [7,8]. Undoubtedly, family education is the core of the whole education, and it has the key meaning that can't be replaced. It is also the most easily neglected link in the training process of the competitive sports institutions. Since family education is the earliest education, parents' personalities often exert a great influence on their children' hearts, and build up the unbreakable marks at the same time. Therefore, through parents open day, parents advisory activities, family open letters and other ways, parents further realize that the competitive level and personality power constitute the two main pillars of young athletes' growth at present. The comprehensive personality construction and development of young athletes will not only result from the atmosphere and environment of school and family, but also exert a series of influences on the diversity of social atmosphere. Therefore, we must create a multi-channel, multi-level, all-round, the social education network arranged in a crisscross pattern, the good social atmosphere, positive public opinion guidance and developed information dissemination media, vigorous promotion of models, and change the prejudice from the outside world toward the young athletes of sports college, which will have an important impact on healthy personality of young athletes.

\section{Conclusion}

The content of personality education is more extensive. Through the implementation of all-round personality education, we can promote a series of fine basic qualities of young athletes, such as modesty, frankness, friendliness and self-respect, and self-esteem, self-reliance, pioneering spirit, pragmatic diligence, and the eligible self-cognition and positive mental health and so on. They can scientifically deal with the organic relation among people, people and society, people and nature. Young athletes who own the perfect personality is an important condition for to achieve their 
self-value, an important guarantee of striving for medals and educating people and an important guarantee of the sustainable development of Chinese competitive sports.

\section{Acknowledgement}

This work was supported in part by the Project of the Fundamental Research Funds for the Central Universities under Grant LGZD201709, in part by the Project of China Postdoctoral Science Foundation under Grant 2017M611849, in part by Jiangsu Qing LAN Project under Grant 2017, and in part by Nanjing Forest police College Teaching Reform Project under Grant ZD17001 \& YB17001.

\section{References}

[1] Cheng, C.Z. (2013) Sportsmanship and Character Education in the Process of Training (Natural Science). Journal of Nanjing Institute of Physical Education (Natural Science), 4, 61-63. (In Chinese)

[2] Yin, Y. (2011) Discussion on sports spirit and personality education in sports training teaching. Sporting events: an academic edition, 4, 38-39. (In Chinese)

[3] Miao, X.L. (2005) Discussion on the Character Education both in PE Teaching and Sports. Journal of Harbin Physical Education Institute, 4, 68-69. (In Chinese)

[4] Liu, S.H. (2012) From skills to culture: on the education of athletes' success in the new era. Sports Culture Guide, 10, 62-65. (In Chinese)

[5] Han, X.Y. (2012) On the personality characteristics and adult education of young athletes. Vocational Education Forum, 5, 74-75. (In Chinese)

[6] Fang,P.S., Zhang,X., Liang, C.M. (2008) Athlete's Personality Case Study and Its Difference Analysis in Sport Event. China Sport Science and Technology, 1, 21-24. (In Chinese)

[6] Wang, C.,WANG,Y.S. (2017) Research on the Core Values of Competitive Sports in Harvard University. Journal of Beijing Sport University, 1, 35-40. (In Chinese)

[8] Zheng, L.X. (2017) Research on Cultural Education of Athletes in China-Reflection on the phenomenon of "using force" in athletes. Journal of Guangzhou Sport University, 1, 57-61. (In Chinese) 